\title{
A Case of Excessive Post-Tonsillectomy Hemorrhage Requiring Ligature of the External Carotid Artery
}

\author{
Yoshihiko Nakata $^{1)}$, Ken Ishijima ${ }^{2)}$ and Hiroaki Sato ${ }^{3)}$
}

\begin{abstract}
Ligature of the external carotid artery (LECA) is a very effective method of choice in patients with excessive post-tonsillectomy hemorrhage. We report herein on the case of a 25-year-old man who underwent LECA for an excessive post-tonsillectomy hemorrhage. His tonsillectomy had been performed under general anesthesia for habitual angina seven days previously. One morning abrupt and excessive bleeding occurred and the patient went into shock. Immediate LECA was performed under general anesthesia. The bleeding was stopped rapidly and a blood transfusion was performed. The patient was discharged 16 days after the LECA without any severe complications.
\end{abstract}

Keywords : tonsillectomy, hemorrhage, ligature, external carotid artery

\section{References}

1）牛飼雅人，黒野祐一：扁桃手術におけるトラブルの予防と 対応. JOHNS 19: 403-406, 2003.

2) 武山 勇：扁桃と医事問題. JOHNS 1：885-890, 1985.

3）武田広誠, 甲斐智朗：扁摘および関連手術の術後 10 日過ぎ 出血 3 症例。耳鼻展望 42：46-49, 1999.

4）土井 彰, 田村耕三，赤木博文 : 口蓋扁桃摘出術 : 術後出 血例の検討. 口腔咽頭科 20：305-310, 2008 .

5) Okada M, Kobayashi T and Nakamura K : Post-tonsillectomy hemorrhage in adult patients. Pract Otol (Kyoto) 102: 219223, 2009.

6) Ishida R, Nakamura S, Fuke T, et al. : Post-tonsillectomy hemorrhage: a retrospective study of 503 operations. Pract Otol (Kyoto) 99: 319-395, 2006.

7）丸笹直子, 岩井 大, 吉永和仁, 他：口蓋扁桃摘出術にお ける術後出血の検討． 口腔咽頭科 13：237-241, 2001.

8）朴澤孝治:扁桃摘出術後のトラブル.JOHNS 23：1116-1120,
2007.

9) Nagase T, Waki T, Okazaki M, et al. : Tonsil surgery evaluated by otolaryngologists with special reference to postoperative complications. Pract Otol (Kyoto) Suppl 130: 95-100, 2011.

10）川内秀之, 小笠原圭子：口蓋扁桃摘出のコツ一術前, 術後 の注意を含めて一. ENTONI 11：10-17, 2002.

11）飯田 実, 石井正則, 秋山香織，他：口蓋扁桃摘出後 4 日 目に大量出血をきたした 1 症例. 耳鼻展望 41：151-153, 1998.

12）関谷 透: 扁摘の術後出血処理. JOHNS 2: 982-986, 1986.

13) Windfuhr JP : Excessive post-tonsillectomy hemorrhage requiring ligature of the external carotid artery. Auris Nasus Larynx 29: 159-164, 2002.

14) Furuya A, Yamada Y, Kikuchi H, et al. : A study of 8 cases undergoing ligation of the external carotid artery in our department. Pract Otol (Kyoto) 99: 789-793, 2006.

15）夜陣紘治，立川隆治：鼻出血の手術的治療. JOHNS 16: 1629-1633, 2000.
1) Department of Otolaryngology, Iwate Prefectural Isawa Hospital

2) Department of Otolaryngology, Fukui Red Cross Hospital

3) Department of Otorhinolaryngology, Iwate Medical College
Corresponding Author Address : Yoshihiko Nakata ysnkt21@nifty.com 